\title{
Bio-herbicide potential of naturalised Desmodium uncinatum crude leaf extract against the invasive plant species Parthenium hysterophorus
}

Fredrick Ojija ${ }^{1,3}$, Sarah E.J. Arnold ${ }^{2}$, Anna C. Treydte ${ }^{1,4}$

${ }^{1}$ Department of Sustainable Agriculture, Biodiversity and Ecosystem Management, School of Life Sciences and BioEngineering, The Nelson Mandela African Institution of Science and Technology, P.O. Box 447, Arusha, Tanzania

${ }^{2}$ Natural Resources Institute, University of Greenwich, Chatham Maritime ME4 4TB, UK. Email: s.e.j.arnold@greenwich.ac.uk

${ }^{3}$ Institute of Science and Technology, Mbeya University of Science and Technology, P.O. Box 131, Mbeya, Tanzania

${ }^{4}$ Hans Ruthenberg Institute, Agroecology in the Tropics and Subtropics, University of Hohenheim, Garbenstr. 13, 70599

Stuttgart, Germany. Email: anna.treydte@nm-aist.ac.tz

Corresponding author: fredrick.ojija@ yahoo.com, orcid.org/0000-0002-1117-5119

\begin{abstract}
The exotic plant Parthenium hysterophorus is rapidly invading ecosystems in sub-Saharan Africa, with negative effects on the environment, economy and human and animal health. With the exception of some synthetic herbicides, none of the available management methods have been effective against $P$. hysterophorus, and carry risks to the environment. Therefore, additional management methods must be explored for an effective integrated approach. Despite the fact that bio-herbicides are considered cost-effective and eco-friendly in mitigating biological invasions, little work has been done to utilize them for controlling P. hysterophorus. We investigated allelopathic effects and, thus, bio-herbicide potential of naturalised Desmodium uncinatum leaf (DuL) crude extract in various concentrations to control P. hysterophorus. Our results revealed that DuL crude extract can suppress P. hysterophorus, particularly at higher concentrations. The $75 \%$ and 100\% DuL crude extract concentrations reduced the total leaf chlorophyll content by $26 \%$ and $22 \%$ in pots and plots, respectively. Further, these higher concentrations inhibited $P$. hysterophorus seed germination by $73 \%$ in petri dishes, $60 \%$ in pots, and $57 \%$ in plots, and negatively interfered with seedling growth vigour. Seedling stem heights under $75 \%$ and $100 \%$ DuL concentrations in pot and plot experiments was about $30 \%$ and $36 \%$ shorter than those sprayed with lower concentrations $(<70 \%)$ and the control, respectively. We show that naturalised plants with allelochemicals can be used as a management tool for controlling P. hysterophorus infestations in sub-Saharan Africa, particularly in Tanzania, and this method should become part of an integrated control toolkit being deployed in a communitybased approach.
\end{abstract}

Key words: Allelopathy, Bio-herbicide, Exotic invasive, Management, Pot experiment, Tanzania

\section{Introduction}

Biological invasions occur when species are introduced into new habitats (Qasem and Foy 2001; Hejda et al. 2009; Ngondya et al. 2016b; Ellison and Cock 2017; Pratt et al. 2017). Species introduction threatens biological conservation, ecosystems services, species diversity and food security (Ellison and Cock 2017; Pratt et al. 2017; Witt et al., 2018; Bajwa et al. 2019). Many invasive plant species including Parthenium hysterophorus are prolific in nature, and have rapid dispersal mechanisms, long seed dormancy, persistent seed banks, and capable of modifying their seeds to adapt in new habitats (Qasem and Foy 2001; Axmacher and Sang 2013; Adkins and 
Shabbir 2014; Gioria et al. 2019). In addition, some invasives lack effective natural enemies in their exotic range due to anti-microbial or anti-herbivory properties (Hinz and Schwarzlaender 2004; Cappuccino and Carpenter 2005). Further, most invasives use allelopathy to inhibit growth of adjacent native plants (Callaway et al. 2008), and develop monospecific patches (Christina et al. 2015). Allelopathy is an effect of one plant species on seeds germination, growth, and development of another adjacent plants by the release of allelochemicals into the environment (Callaway et al. 2008). Thus, heavy infestations of invasive plants can cause changes in ecosystem structure and function (Cappuccino and Carpenter 2005; Adhikari et al. 2015) and subsequently biological and economic losses (Callaway et al. 2008; Bajwa et al. 2019). While suppressing of invasives is often attempted, many approaches have been unsuccessful (Shabbir et al. 2013; Kaur et al. 2014), damaging to the rest of the environment (Ngondya et al. 2016a) and highly expensive (Mcconnachie et al., 2011; Pratt et al., 2017).

Parthenium hysterophorus L. (Asteraceae) is an annual herb originating from North and South America (Kaur et al. 2014; Shrestha et al. 2015; Ojija et al. 2019). In sub-Saharan Africa, P. hysterophorus has invaded many habitats, both in natural and semi-natural ecosystems (Dhileepan 2012; Shabbir et al. 2013; Clark and Lotter 2011). Its allelochemicals are toxic to most native plants, strongly changing habitat vegetation structure where it has established (Kija et al. 2013; Brunel et al. 2014; Shrestha et al. 2015; Wabuyele et al. 2015). Its Partheninsesquiterpene lactones are also toxic to mammals, causing haemorrhage in internal organs of animals due to tissue damage (Kaur et al. 2014). In Tanzania, P. hysterophorus has had ecologically (Ojija et al. 2019) and economically negative effects on livelihoods and natural ecosystems because it interferes with the human welfare, production of fodder and crops (Mcconnachie et al., 2011; Witt et al., 2018). Therefore, its management is vital to ensure ecological integrity of rangelands and protected areas. Biological control is recognised by the Global Invasive Species Programme as ecologically-friendly and sustainable management approach for invasive alien plants compared to synthetic herbicides (Ellison and Cock 2017). While trials of biological control of P. hysterophorus using the leaf eating beetle Zygogramma bicolorata at the Tropical Pesticide Research Institute (TPRI) are underway in Tanzania, other management methods are required for an integrated approach because a single method per se cannot suppress this invasive species (Shabbir et al. 2013; Kaur et al. 2014).

Often, synthetic herbicides have been asserted as the only solution, even although they cause damage to the environment and human health (Hinz and Schwarzlaender 2004; Shabbir et al. 2013; Adkins and Shabbir 2014). Synthetic herbicides are often broad-spectrum and would thus have deleterious non-target effects on native, threatened or ecologically valuable plant species (Ngondya et al. 2016b; Ellison and Cock 2017). They can have lethal or sub-lethal impacts on beneficial invertebrates such as insect natural enemies, pollinators (Balbuena et al. 2015), and decomposers, as well as soil macrobes and microbes, which play a vital role in nutrient cycling (Frimpong et al. 2018). Also, persistent application of herbicides may change soil and water physical-chemical properties (Qasem and Foy 2001; Yu et al. 2018). Because of this, their application is not recommended in natural and semi-natural habitats such as pastures, protected areas and wetlands (Ngondya et al. 2016b; Ellison and Cock 2017). Previous studies have shown that bio-herbicide potential of native or naturalised plants can be used to suppress germination, growth and development of invasive species (Zhao et al. 2008; Ngondya et al. 2016a, b; Ming Chen and Lin Peng 2018). The natives or naturalised are preferred over invasive plants because the former have co-evolved with the allelochemicals of the wider ecological community (Zhao et al. 2008), and their non- 
target impacts are likely to be less severe compared to allelopathic traits of invasive species. Conversely, because exotic invasive plants have not co-evolved with native species, they could release allelochemicals which suppress the growth of natives (Christina et al. 2015). Thus, if the allelopathic traits of certain invasive are used to control other invasive plants, it might kill adjacent native plants and be deleterious to the wider flora (Zhao et al. 2008; Christina et al. 2015; Ming Chen and Lin Peng 2018).

To our knowledge, no previous studies have, yet, investigated naturalised plant bio-herbicidal potentials to suppress $P$. hysterophorus in Tanzania, albeit bio-herbicide extracts from naturalised plant $D$. uncinatum might be a potential ecological-friendly management option. Our study, therefore, is a catalyst to progress the utilisation of allelopathic traits of naturalised plants to fight against $P$. hysterophorus. We investigated the allelopathic effect of naturalised plant Desmodium uncinatum (Fabaceae) leaf crude extract (DuL) in suppressing seed germination and seedling growth of $P$. hysterophorus. We chose $D$. uncinatum because its bio-herbicide potential was previously documented to suppress growth and germination of the invasive species Tagetes minuta (Ngondya et al. 2016a) and Gutenbergia cordifolia (Ngondya et al. 2016b) in Tanzania, and Striga hermonthica in Kenya (Guchu et al. 2007; Hooper et al. 2010). We used lab, pot and field plot experiments to quantify the effect of different DuL crude extract concentrations on seed germination and seedling growth of $P$. hysterophorus. We predicted that DuL crude extract will negatively affect germination, seedling height, biomass and chlorophyll content of $P$. hysterophorus as observed for other invasive plants in Tanzania (Ngondya et al. 2016a, b).

\section{Materials and methods}

\section{Desmodium uncinatum leaf crude extract}

Fresh leaves of D. uncinatum, were collected from individuals across five villages (Nkwaranga, Ngiresi, Sokoni one, Sura, and Urisho) in Meru district of Arusha region, between June and August 2018. During this time period the plants were abundant, and weather conditions were suitable (i.e. little rainfall) for collecting leaf samples. The leaves were collected early in the morning before sunrise to avoid possible degradation of any non-photostable allelochemicals. About 10 to 20 leaves were collected randomly from different individual plants of different ages occurring on non-agriculture areas, and free from pesticide contamination (Isman and Grieneisen 2014). Voucher specimens were taken to the National Herbarium of Tanzania (NHT) at TPRI for identification and retained there for future taxonomic validation. The leaves were air dried for about 30 days under room temperature in shade (or indoors) to prevent ultraviolet (UV) light from degrading some compounds. Dried leaves were ground into fine powder and stored in porous paper envelopes. Preparation of DuL crude extract concentrations followed procedures described by Ngondya et al. (2016a,b), whereby $100 \mathrm{~g}$ powder was soaked in 11 of distilled water to form crude extract $(10 \mathrm{w} / \mathrm{v})$. Crude extract was stored in a 41 plastic container for $72 \mathrm{~h}$ in a dark room. The extract was filtered using Muslin cloth and filtrates were diluted with distilled water to obtain different aqueous concentrations of DuL (100 ml each) termed $0 \mathrm{~g} / \mathrm{l}(0 \%), 0.025 \mathrm{~g} / \mathrm{l}(25 \%), 0.05 \mathrm{~g} / \mathrm{l}(50 \%), 0.75 \mathrm{~g} / \mathrm{l}(75 \%)$, and $0.1 \mathrm{~g} / \mathrm{l}(100 \%)$ relative to the original extract (i.e. the $25 \%$ concentration was actually equal to a $2.5 \mathrm{w} / \mathrm{v}$ extract suspension, etc.) (Ngondya et al. 2016a,b).

\section{Seed germination experiment}

Parthenium hysterophorus seeds were obtained from the Agricultural Division at TPRI. To investigate the allelopathic effect of DuL crude extract on P. hysterophorus seed germination, experiments were conducted at the 
Nelson Mandela African Institution of Science and Technology (NM-AIST), Tengeru campus ( $3^{\circ} 24.149^{\prime}$ S and $36^{\circ} 47.790^{\prime} \mathrm{E}, 1197 \mathrm{~m}$ a.s.1), in the lab (for petri dishes), and field (for pots and plots). Five glass petri dishes (each of $70.8 \mathrm{~cm}^{2}$ surface area), five plastic pots $\left(763.8 \mathrm{~cm}^{2}\right.$ surface area), and five field plots $\left(1 \mathrm{~m}^{2}\right)$ per treatment were used, and then replicated five times. Petri dishes lined with absorbent cotton wool were rinsed with distilled water before 25 seeds of $P$. hysterophorus were sown in each dish. The same number of seeds were sown in pots and plots. Respectively, each petri dish, pot, and plot was moistened with $10 \mathrm{ml}, 50 \mathrm{ml}$, and 450ml of the different DuL concentration treatments $0 \mathrm{~g} / \mathrm{l}(0 \%), 0.025 \mathrm{~g} / \mathrm{l}(25 \%), 0.05 \mathrm{~g} / \mathrm{l}(50 \%), 0.75 \mathrm{~g} / \mathrm{l}(75 \%)$, and 0.1 g/l (100\%). While petri dishes were moistened only once, pots and plots were moistened once every day for entire experimental period. Plots were equally spaced $0.5 \mathrm{~m}$ apart. The position of petri dishes and pots was randomised weekly throughout the experiment in order to ensure equal distribution of sunlight and ensure more consistent coverage of water. The number of seeds that germinated (sensu Ngondya et al. 2016a,b) were recorded daily for 20 days, and the percentage of seeds germinated was calculated. Germination inhibition percentage (IP) of treatments over the control germination were also calculated $(i)$.

$$
\mathrm{IP}=\left(\frac{\text { Germinated seeds in extracts }- \text { Germinated seeds in control }}{\text { Germinated seeds in control }}\right) * 100 \ldots \ldots \ldots \ldots i
$$

\section{Seedling growth experiment}

Twenty-five field plots of $1 \mathrm{~m}^{2}$ were planted with 40 seeds each. At the same time, the same number of seeds was planted in each 25 pots using soil from the field plots. Plots/pots were watered thoroughly at the time of sowing (i.e. 0.51 and 41 per pot and plot, respectively). Following a week of germination, plots/pots were irrigated twice per week. Seedlings were thinned to three per pot to prevent overcrowding. 20-day-old seedlings in each pot and plot were sprayed with $50 \mathrm{ml}$ and $100 \mathrm{ml}$ of the different DuL crude extract concentrations (i.e. 0 g/l $(0 \%), 0.025$ $\mathrm{g} / \mathrm{l}(25 \%), 0.05 \mathrm{~g} / \mathrm{l}(50 \%), 0.75 \mathrm{~g} / \mathrm{l}(75 \%)$, and $0.1 \mathrm{~g} / \mathrm{l}(100 \%))$ once every day for 25 days (2 August to 19 September 2018) using a hand sprayer, respectively. The allelopathic effects of DuL crude extract on seedling growth at different concentrations were investigated by measuring stem heights, stem diameters, root lengths, biomass, and total leaf chlorophyll content (Chl). At the end of the experiments, ten $P$. hysterophorus seedlings (64 days old) per treatment were randomly harvested from each plot and three from each pot without destroying the roots. Growth parameters i.e., stem or shoot height, stem diameter, root length, aboveground fresh biomass (AFB), aboveground dry biomass (ADB), belowground fresh biomass (BFB), and belowground dry biomass (BDB) were measured. In order to determine AFB, ADB, BFB, and BDB, the seedlings were washed to remove dirt and separated into above- and below ground biomass components as an index of productivity (Ammondt and Litton 2012). Each biomass component in separate paper bags was dried in an oven at $70^{\circ} \mathrm{C}$ for $12 \mathrm{~h}$. Stem height and root length were measured using a meter ruler, biomass with an analytical balance. The stem diameter was measured above the first two leaves of the seedlings with digital callipers.

\section{Measurement of leaf chlorophyll content}

We randomly selected five leaves from ten seedlings per plot and three seedlings per pot after 25 days of spraying with different concentrations of DuL crude extract and control. Total Chl content of $P$. hysterophorus seedlings in field plots/pots was extracted (Hiscox and Israelstam 1979), analysed and used as index of plant health in response to DuL treatments. The total $\mathrm{Chl}$ content was extracted, whereby $70 \mathrm{mg}$ of young fresh leaves was 
immersed in $6 \mathrm{ml}$ of dimethyl sulfoxide (DMSO) without grinding, and incubated at $65^{\circ} \mathrm{C}$ for $12 \mathrm{~h}$. The extract was transferred to a test tube and made up to a total volume of $10 \mathrm{ml}$ with DMSO, thereafter, transferred to vials for storage $\left(0-4^{\circ} \mathrm{C}\right)$ waiting for analysis. A $3 \mathrm{ml}$ chlorophyll extract of $P$. hysterophorus was transferred into glass cuvettes to determine absorbance or optical density (OD) of the sample. The OD of blank liquid (DMSO) and samples was determined under 2800 UV/VIS spectrophotometer (UNICOß) at $663 \mathrm{~nm}$ and $645 \mathrm{~nm}$ (Hiscox and Israelstam 1979). The absorbance of the blank was deducted from the absorbance readings of every sample prior to calculations being made. DuL chlorophyll contents were calculated using the equation (ii), where A663 and A645 are absorbance readings at $663 \mathrm{~nm}$ and $645 \mathrm{~nm}$, respectively (Hiscox and Israelstam 1979; Ngondya et al. 2016a, b).

$$
\text { Total Chl }=0.0202 A 663+0.00802 A 645 \ldots \ldots \ldots \ldots \ldots i i
$$

\section{Statistical data analysis}

Comparisons of $P$. hysterophorus seedling germination, and growth parameters (stem height, stem diameter, root length, AFB, ADB, BFB, BDB, and Chl) were compared for different concentrations of DuL crude extract using a one-way ANOVA. We verified normality and homogeneity of variance using Shapiro-Wilk test and Levene's test respectively. Significant differences were further compared using the post-hoc Fisher LSD test. The statistical software used for all tests was Origin (2013) version 9.0 SR1 at a significance level of 5\%.

\section{Results}

\section{Seed germination under treatments}

The germination of $P$. hysterophorus seeds was delayed at higher concentrations $(>70 \%)$ of DuL crude extract compared to lower concentrations (Fig 1a-c). Under 25\% DuL concentrations and in the control treatment, seedlings had emerged at day 3 (Fig 1a-c). Under 100\% DuL concentrations, P. hysterophorus seed germination was suppressed by $73 \%$ in petri dishes $\left(F_{(4,20)}=13.88, P<0.0001\right), 60 \%$ in pots $\left(F_{(4,20)}=17.82, P<0.0001\right)$, and $57 \%$ in plots $\left(F_{(4,20)}=18.73, P<0.0001\right)$ (Table 1). In general, the seed germination inhibition increased with increasing DuL crude extract concentration treatment (Table 1).

Table 1 Mean $( \pm$ SE) germination percentage and germination inhibition percentage of $P$. hysterophorus seeds under different concentrations of Desmodium uncinatum (DuL) crude extract over a 20 days experiment in petri dishes, pots, and field plots. Values with different letter (s) in a row are significantly different by Fisher LSD at $P$ $=0.05$.

Fig.1 Number of Parthenium hysterophorus seeds that germinated under different concentration treatments (i.e. 0\%, 25\%, 50\%, 75\%, 100\%) of Desmodium uncinatum leaf crude extract in petri dishes (a), pots (b), and plots (c) over the experimental period of 20 days. Desmodium uncinatum leaf crude extract delayed P. hysterophorus seed germination at higher concentrations

\section{Seedling growth parameters under treatments}

Stem height of $P$. hysterophorus seedlings sprayed with DuL concentrations differed significantly in both plot and pot experiments $\left(F_{(4,20)}=11.21, P=0.0001\right.$, and $F_{(4,20)}=16.87, P<0.0001$ respectively, Fig $\left.2 \mathrm{a}\right)$. Mean $( \pm \mathrm{SE})$ stem height of seedlings sprayed with $75 \%$ and $100 \%$ concentrations of DuL crude extract in the plot experiment 
$(21 \pm 0.2 \mathrm{~cm}$ and $20.3 \pm 0.5 \mathrm{~cm}$ respectively, Fig $2 \mathrm{a})$ was about $36 \%$ shorter than those sprayed with lower concentrations $(<70 \%)$ and control. In the pot experiment, stem height in $75 \%$ and $100 \%$ treatments (Mean \pm SE: $11.3 \pm 0.4 \mathrm{~cm}, 75 \%$; and $12.1 \pm 0.5 \mathrm{~cm}, 100 \%$, respectively, Fig $2 \mathrm{a})$ was approximately $30 \%$ shorter than that sprayed with lower DuL concentrations (i.e. $<50 \%$ ). The root length of $P$. hysterophorus seedlings sprayed with DuL crude extract concentrations differed significantly in both plot and pot experiments $\left(F_{(4,20)}=27.80, P<\right.$ 0.0001 , and $F_{(4,20)}=3.83, P=0.0181$ respectively, Fig $2 \mathrm{~b}$ ). The root length of seedlings in 50\%, $75 \%$, and $100 \%$ concentrations of DuL in plot experiment were about $45 \%$ shorter than those sprayed with $25 \%$ of DuL concentration and control (Fig 2b). In pot experiments, the root length was about $51 \%$ shorter in plants sprayed with $75 \%$ or higher concentrations than those sprayed with $25 \%$ and $50 \%$ concentrations (Mean \pm SE: $7.7 \pm 0.6$ $\mathrm{cm}, 75 \%$; and $8.8 \pm 0.6 \mathrm{~cm}, 100 \%$, Fig $2 \mathrm{~b}$ ).

The stem diameter of $P$. hysterophorus seedlings differed significantly under different DuL concentrations in both plot and pot experiments $\left(F_{(4,20)}=3.19, P=0.0351\right.$, and $F_{(4,20)}=12.26, P<0.0001$ respectively, Fig $\left.2 \mathrm{c}\right)$. The diameter of seedlings sprayed with 50\%,75\%, and 100\% concentrations of DuL in plot experiments was slightly smaller than those sprayed with $25 \%$ concentration of DuL (Fig 2c). In the pot experiments the stem diameter was approximately $31 \%$ smaller than those sprayed with $25 \%$ and $50 \%$ concentrations (Mean \pm SE: $2.4 \pm 0.1 \mathrm{~mm}$, $75 \%$, and $2.2 \pm 0.2 \mathrm{~mm}, 100 \%$, Fig $2 \mathrm{c}$ ).

Fig.2 Stem height (a), root length (b), and stem diameter (d) of Parthenium hysterophorus seedlings treated with Desmodium uncinatum leaf crude extract for 25 days in field plots (left panels) and pots (right panels) experiments under different concentration. Boxplots show the mean (a square within boxes) and ranges from $25 \%$ and $75 \%$ quartile, and the tips of the whiskers indicate standard deviation. Boxes with different letter(s) are significantly different by Fisher LSD at $P=0.05$.

Average above ground fresh biomass (AFB) of $P$. hysterophorus seedlings differed significantly with DuL crude extract concentrations in both field $\operatorname{plot}\left(F_{(4,20)}=3.31, P=0.031\right)$ and $\operatorname{pot}\left(F_{(4,20)}=16.16, P<0.0001\right)$ experiments (Fig 3). Also, the below ground fresh biomass (BFB) in field plots and pots experiments was significantly different between treatments $\left(F_{(4,20)}=51.85, P=0.031\right.$, and $F_{(4,20)}=15.95, P<0.0001$ respectively, Fig 3$)$. In both plot and pot experiments, the seedlings sprayed with $100 \%$ concentration of DuL crude extract were observed to have lower AFB and BFB. Respectively, the AFB in plots and pots (Mean \pm SE: $110.1 \pm 6.1 \mathrm{~g}$, plots, and 10.7 $\pm 0.9 \mathrm{~g}$, pots) was about $33 \%$ and $30 \%$ smaller than AFB in lower concentrations. Similarly, the BFB (Mean \pm SE: $6.2 \pm 0.3 \mathrm{~g}$, plots, and $2.1 \pm 0.3 \mathrm{~g}$, pots) was about $60 \%$ and $78 \%$ smaller than BFB in lower concentrations in plots and pots experiments respectively (Fig 3 ).

Fig.3 Above and below ground fresh biomass (AFB and BFB respectively) of Parthenium hysterophorus seedlings sprayed with Desmodium uncinatum leaf crude extract for 25 days in field plots (left panels) and pots (right panels) experiments under different concentration. Boxplots show the mean (a square within boxes) and ranges from $25 \%$ and $75 \%$ quartile, and the tips of the whiskers indicate standard deviation. Boxes with different letter(s) are significantly different by Fisher LSD at $P=0.05$.

Average above ground dry biomass (ADB) of $P$. hysterophorus seedlings differed significantly under DuL crude extract concentrations in both field plots $\left(F_{(4,20)}=6.30, P=0.0019\right)$ and pots $\left(F_{(4,20)}=42.39, P<0.0001\right)(\mathrm{Fig} 4)$. Similarly, below ground dry biomass $(\mathrm{BDB})$ in field plots and pots experiments was significant different $\left(F_{(4,20)}\right.$ 
$=5.14, P=0.0052$, and $F_{(4,20)}=13.19, P<0.0001$ respectively, Fig 4). The seedlings sprayed with $100 \%$ concentration of DuL crude extract were observed to have lower ADB and BDB in both experiments. Respectively, the ADB in plots and pots (Mean \pm SE: $10.1 \pm 0.8 \mathrm{~g}$, plots, and $2.1 \pm 0.1 \mathrm{~g}$, pots) was $41 \%$ and $50 \%$ smaller than the ADB in lower concentrations. The BDB of seedling under high DuL concentration treatments in pots (Mean \pm SE: $0.7 \pm 0.5 \mathrm{~g}$ ) was about $67 \%$ smaller than that in lower concentration (Fig 4). With $75 \%$ and $100 \%$ DuL concentrations, the BDB in plots was considerably reduced (i.e. > 75\%) compared to BDB in lower concentrations (Mean \pm SE: $0.7 \pm 0.0 \mathrm{~g}$, Fig 4).

Fig.4 Above and below ground dry biomass (ADB and BDB respectively) of Parthenium hysterophorus seedlings sprayed with Desmodium uncinatum leaf crude extract for 25 days in field plots (left panels) and pots (right panels) experiments under different concentration. Boxplots show the mean (a square within boxes) and ranges from 25\% and $75 \%$ quartile, and the tips of the whiskers indicate standard deviation. Boxes with different letter(s) are significantly different by Fisher LSD at $P=0.05$

\section{Total chlorophyll content}

Total leaf chlorophyll content (Chl) of $P$. hysterophorus seedlings differed significantly between concentrations of DuL crude extract in both plots and pots experiments $\left(F_{(4,20)}=54.96, P<0.0001\right.$, and $F_{(4,20)}=6.86, P=0.0012$, respectively, Fig 5). Seedlings sprayed with higher DuL concentrations (75\% and 100\%) had lower total Chl content (i.e. $<22 \%$ and $26 \%$ in plots and pots respectively) than those sprayed with lower concentrations (Fig 5).

Fig.5 Total leaf chlorophyll content of Parthenium hysterophorus seedling sprayed with Desmodium uncinatum leaf crude extract for 25 days in pots (a) and field plots (b) experiments under different concentration. Boxplots show the mean (a square within boxes) and ranges from $25 \%$ and $75 \%$ quartile, and the tips of the whiskers indicate standard deviation. Boxes with different letter(s) are significantly different by Fisher LSD at $P=0.05$

\section{Discussion}

Our study revealed that crude leaf extract of naturalised plant $D$. uncinatum can suppress $P$. hysterophorus at various phenological stages, i.e., both seedling germination and growth, particularly under high concentrations of $75 \%$ and above. Efficient of D. uncinatum extract at high concentration agrees with studies claiming that the effectiveness of bio-herbicide is dose dependent (Khaliq et al. 2011; Ngondya et al. 2016b). Interaction of natives with alien invasive plants is affected by their non co-evolutionary background (Christina et al. 2015). Based on the 'novel weapon' hypothesis, most native species are not adapted to the biochemical traits of invasive species (Callaway et al. 2008). The flipside of the 'novel weapon' hypothesis or 'homeland security' hypothesis is that within the invasive range, the plant chemistry of native or naturalized plants (e.g. D. uncinatum) may be able to suppress the growth of invasive species in turn (Cummings et al. 2012). Since D. uncinatum and $P$. hysterophorus have not co-evolved, the latter may be poorly adapted to the bio-herbicide potential of the former species (Christina et al. 2015). Findings of our study support this 'homeland security' hypothesis and showed that $D$. uncinatum bio-herbicidal exerts resistance against the $P$. hysterophorus invasion process due to its allelochemicals.

Our results showed that high concentrations of $D$. uncinatum leaf extract delayed $P$. hysterophorus seed germination. This reveals the potential to interfere early in the germination stage of $P$. hysterophorus and suppress 
its seeds in the soil, preventing further invasions. In addition, the growth parameters and total leaf chlorophyll content of $P$. hysterophorus seedlings were suppressed slightly under low concentrations but more strongly under high concentration treatments, which agrees with findings by Khaliq et al. (2011), Cipollini and Flint (2013), and Ngondya et al. (2016a). This was likely due to D. uncinatum leaf extract, which has active bio-herbicidal properties as previously reported in other studies (Guchu et al. 2007; Khan et al. 2008; Hooper et al. 2010; Ngondya et al. 2016a, b). Hooper et al. (2010) and Pickett et al. (2013) reported that the genus Desmodium can suppress parasitic weeds such as Striga hermonthica through allelopathy when intercropped with cereals like sorghum, maize and millet. Allelochemicals of $D$. uncinatum root extract effective against the development of $S$. hermonthica include isoschaftoside, a C-glycosylflavonoid (Hooper et al. 2010), and uncinanone (4",5"-dihydro2'-methoxy-5,4'-dihydroxy-5"-isopropenylfurano-(2",3";7,6)-isoflavanone) (Tsanuo et al. 2003; Guchu et al. 2007). These may also be present in leaf extract and responsible for inhibition of germination and growth of $P$. hysterophorus in our study, which can help to control the spread of P. hysterophorus. Nevertheless, further chemical identification of specific allopathic compounds present in leaf exudate is essential to understand its effectiveness.

In our study, Desmodium uncinatum crude leaf extract had the ability to weaken $P$. hysterophorus seedlings' growth. However, $P$. hysterophorus, like many invasive plants, probably cannot be eradicated using one method per se, and necessitates an integrated management approach (Shabbir et al. 2013; Shrestha et al. 2015; Terblanche et al. 2016). As $P$. hysterophorus can regrow from broken or cut parts and can become resistant to any chemical control method, Adkins and Shabbir (2014) and Nyasembe et al. (2015) suggested that traditional weeding and chemical approaches need to be combined with a wider strategy. For example, P. hysterophorus management using the $D$. uncinatum bio-herbicide could be complemented with biological control agents such as Mexican beetle Zygogramma bicolorata (Shabbir et al. 2013), metabolites of fungal species (Javaid 2010), or bioherbicides from other native or naturalised allelopathic plants (Javaid 2010; Tanveer et al. 2015). In addition, $P$. hysterophorus might be suppressed by seeding competitive suppressive plants and by uprooting and burning of P. hysterophorus seedlings before they flower or release seeds (Shabbir et al. 2013). These measures are only possible with an involvement of local communities to reach long-term sustainability. Similarly, there is a need for a coordinated, national strategy for controlling invasive species linking all management approaches to achieve effective and sustainable control of P. hysterophorus (Terblanche et al. 2016). Moreover, timely detection and control (i.e. using bio-herbicides) of $P$. hysterophorus before it invades other habitats are essential for preventing its spreads (Crall et al. 2013; Maistrello et al. 2016) and reducing management cost (Crall et al. 2013).

Therefore, naturalised D. uncinatum bio-herbicide can be utilized in sub-Saharan Africa to control invasive plants threatening natural and agricultural ecosystems, biodiversity management, and livelihood of smallholders. However, further field studies must be conducted to verify the safety of $D$. uncinatum leaf crude extract for other native plant and animal species (i.e. to avoid suppressing native plants or macro-and-micro invertebrates) before implementation. Similarly, research should be conducted to identify chemical components of natural products, in particular the active components of $D$. uncinatum, which are suitable for large scale, low-impact deployment in $P$. hysterophorus control. We also, recommend that for an effective control of $P$. hysterophorus integrated control approaches are imperative, for example, $D$. uncinatum leaf bio-herbicides could be complemented with existing management methods. In addition to deploying control measures via a community approach, awareness of the 
effects and dispersal mechanisms of $P$. hysterophorus should be raised to local communities so that to prevent new invasions in other habitats.

\section{Conflict of interests}

All the authors declare that there is no conflict of interests. They all agree to submission of this paper.

\section{Acknowledgements}

We acknowledge the support from World Bank through its African Centre of Excellence, "Centre for Research, Agricultural advancement, Teaching Excellence and Sustainability in Food and Nutritional Security (CREATES)", in the School of Life Sciences and Bioengineering at the Nelson Mandela Institution of Science and Technology (NM - AIST) in Arusha, Tanzania, for funding this work. We also thank the Idea Wild for supporting us with research equipment.

\section{References}

Adhikari D, Tiwary R, Barik SK (2015) Modelling hotspots for invasive alien plants in India. PLOS ONE 10:e0134665. doi: 10.1371/journal.pone.0134665

Adkins S, Shabbir A (2014) Biology, ecology and management of the invasive Parthenium weed (Parthenium hysterophorus L.): Management of Parthenium weed. Pest Management Science 70:1023-1029. doi: 10.1002/ps.3708

Ammondt SA, Litton CM (2012) Competition between native Hawaiian plants and the invasive grass Megathyrsus maximus: Implications of functional diversity for ecological restoration. Restoration Ecology 20:638646. doi: 10.1111/j.1526-100X.2011.00806.x

Axmacher JC, Sang W (2013) Plant invasions in China - challenges and chances. PLoS ONE 8:e64173. doi: 10.1371/journal.pone.0064173

Bajwa AA, Farooq M, Nawaz A, et al (2019) Impact of invasive plant species on the livelihoods of farming households: evidence from Parthenium hysterophorus invasion in rural Punjab, Pakistan. Biol Invasions. doi: 10.1007/s10530-019-02047-0

Balbuena MS, Tison L, Hahn M-L, et al (2015) Effects of sublethal doses of glyphosate on honeybee navigation. Journal of Experimental Biology 218:2799-2805. doi: 10.1242/jeb.117291

Brunel S, Panetta D, Fried G, et al (2014) Preventing a new invasive alien plant from entering and spreading in the Euro-Mediterranean region: the case study of Parthenium hysterophorus. EPPO Bulletin 44:479489. doi: 10.1111/epp.12169

Callaway RM, Cipollini D, Barto K, et al (2008) Novel weapons: Invasive plant suppresses fungal mutualists in America but not in its native Europe. Ecology 89:1043-1055. doi: 10.1890/07-0370.1

Cappuccino N, Carpenter D (2005) Invasive exotic plants suffer less herbivory than non-invasive exotic plants. Biology Letters 1:435-438. doi: 10.1098/rsbl.2005.0341 
Christina M, Rouifed S, Puijalon S, et al (2015) Allelopathic effect of a native species on a major plant invader in Europe. The Science of Nature 102:. doi: 10.1007/s00114-015-1263-x

Crall AW, Jordan R, Holfelder K, et al (2013) The impacts of an invasive species citizen science training program on participant attitudes, behavior, and science literacy. Public Understanding of Science 22:745-764. doi: 10.1177/0963662511434894

Cipollini KA, Flint W. (2013) Comparing allelopathic effects of root and leaf extracts of invasive Alliaria petiolata, Lonicera maackii and Ranunculus ficaria on the germination of three native woodland plants. Ohio Journal of Science 112:37-43

Cummings J, Parker I, Gilbert G (2012) Allelopathy: A tool for weed management in forest restoration. Plant Ecology 213:1975-1989. doi.org/10.1007/s11258-012-0154-x.

Dhileepan K (2012) Reproductive variation in naturally occurring populations of the weed Parthenium hysterophorus (Asteraceae) in Australia. Weed Science 60:571-576. doi: 10.1614/WS-D-12-00005.1

Ellison CA, Cock MJW (2017) 10 Classical Biological Control of Mikania micrantha: The sustainable solution. CAB International 162-190. doi: 10.1079/9781780646275.0162

Frimpong JO, Ofori ESK, Yeboah S, et al (2018) Evaluating the impact of synthetic herbicides on soil dwelling macrobes and the physical state of soil in an agro-ecosystem. Ecotoxicology and Environmental Safety 156:205-215. doi: 10.1016/j.ecoenv.2018.03.034

Gioria M, Le Roux JJ, Hirsch H, et al (2019) Characteristics of the soil seed bank of invasive and non-invasive plants in their native and alien distribution range. Biol Invasions 21:2313-2332. doi: 10.1007/s10530019-01978-y

Guchu SM, Yenesew A, Tsanuo MK, et al (2007) C-methylated and C-prenylated isoflavonoids from root extract of Desmodium uncinatum. Phytochemistry 68:646-651. doi: 10.1016/j.phytochem.2006.11.035

Hejda M, Pyšek P, Jarošík V (2009) Impact of invasive plants on the species richness, diversity and composition of invaded communities. Journal of Ecology 97:393-403. doi: 10.1111/j.1365-2745.2009.01480.x

Hiscox JT, Israelstam GF (1979) A method for the extraction of chlorophyll from leaf tissue without maceration. Canadian Journal of Botany 57:1332-1334

Hinz HL, Schwarzlaender M (2004) Comparing invasive plants from their native and exotic range: What can we learn for biological control? Weed Technology 18:1533-1541

Hooper AM, Tsanuo MK, Chamberlain K, et al (2010) Isoschaftoside, a C-glycosylflavonoid from Desmodium uncinatum root exudate, is an allelochemical against the development of Striga. Phytochemistry 71:904908. doi: 10.1016/j.phytochem.2010.02.015

Isman MB, Grieneisen ML (2014) Botanical insecticide research: many publications, limited useful data. Trends in Plant Science 19:140-145. doi: 10.1016/j.tplants.2013.11.005 
Javaid A (2010) Herbicidal potential of allelopathic plants and fungi against Parthenium hysterophorus - A review. Allelopathy Journal 25:331-344

Kaur M, Aggarwal NK, Kumar V, Dhiman R (2014) Effects and management of Parthenium hysterophorus: A weed of global significance. International Scholarly Research Notices. 2014:1-12. doi: $10.1155 / 2014 / 368647$

Khaliq A, Matloob A, Tanveer A, et al (2011) Reduced doses of a sulfonylurea herbicide for weed management in wheat fields of Punjab, Pakistan. Chilean Journal of Agricultural Research 71:424-429. doi: 10.4067/S0718-58392011000300013

Khan Z, Pickett J, Hassanali A, et al (2008) Desmodium species and associated biochemical traits for controlling Striga species: present and future prospects. Weed Research 302-306. doi: doi.org/10.1111/j.13653180.2008.00641.x

Maistrello L, Dioli P, Bariselli M, et al (2016) Citizen science and early detection of invasive species: phenology of first occurrences of Halyomorpha halys in Southern Europe. Biological Invasions 18:3109-3116. doi: $10.1007 / \mathrm{s} 10530-016-1217-\mathrm{z}$

Mcconnachie, A.J., Strathie, L.W., Mersie, W., Gebrehiwot, L., Zewdie, K., Abdurehim, A., Abrha, B., Araya, T., Asaregew, F., Assefa, F., Gebre-Tsadik, R., Nigatu, L., Tadesse, B., Tana, T., 2011. Current and potential geographical distribution of the invasive plant Parthenium hysterophorus (Asteraceae) in eastern and southern Africa: Distribution of Parthenium hysterophorus in eastern and southern Africa. Weed Research. 51, 71-84. https://doi.org/10.1111/j.1365-3180.2010.00820.x

Ming Chen B, Lin Peng S (2018) Allelopathic potential of native invasive plants: The evidence from southern China. Allelopathy Journal 43:43-52. doi: 10.26651/allelo.j./2018-43-1-1128

Ngondya IB, Munishi L, Treydte AC, Ndakidemi PA (2016a) Demonstrative effects of crude extracts of Desmodium spp. to fight against the invasive weed species Tagetes minuta. Acta Ecologica Sinica 36:113-118. doi: 10.1016/j.chnaes.2016.03.001

Ngondya IB, Munishi LK, Treydte AC, Ndakidemi PA (2016b) A nature-based approach for managing the invasive weed species Gutenbergia cordifolia for sustainable rangeland management. SpringerPlus 5:. doi: 10.1186/s40064-016-3480-y

Nyasembe VO, Cheseto X, Kaplan F, et al (2015) The invasive American Weed Parthenium hysterophorus can negatively impact malaria control in Africa. PLOS ONE 10:e0137836. doi: 10.1371/journal.pone.0137836

Ojija F, Arnold SEJ, Treydte AC (2019) Impacts of alien invasive Parthenium hysterophorus on flower visitation by insects to co-flowering plants. Arthropod-Plant Interactions. https://doi.org/10.1007/s11829-01909701-3

Pickett J, Hooper A, Midega CA, Khan Z (2013) Allelopathy. In: Joel D., Gressel J., Musselman L. (eds) Parasitic Orobanchaceae. Springer, Berlin, Heidelberg 459-467. doi: doi.org/10.1007/978-3-642-38146-1_25 
Pratt CF, Constantine KL, Murphy ST (2017) Economic impacts of invasive alien species on African smallholder livelihoods. Global Food Security 14:31-37. doi: 10.1016/j.gfs.2017.01.011

Qasem JR, Foy CL (2001) Weed allelopathy, its ecological impacts and future prospects: A review. Journal of Crop Production 4:43-119. doi: 10.1300/J144v04n02_02

Shabbir A, Dhileepan K, O’Donnell C, Adkins SW (2013) Complementing biological control with plant suppression: Implications for improved management of parthenium weed (Parthenium hysterophorus L.). Biological Control 64:270-275. doi: 10.1016/j.biocontrol.2012.11.014

Shrestha BB, Shabbir A, Adkins SW (2015) Parthenium hysterophorus in Nepal: a review of its weed status and possibilities for management. Weed Research 55:132-144. doi: 10.1111/wre.12133

Tanveer A, Khaliq A, Ali HH, et al (2015) Interference and management of parthenium: The world's most important invasive weed. Crop Protection 68:49-59. doi: 10.1016/j.cropro.2014.11.005

Terblanche C, Nänni I, Kaplan H, et al (2016) An approach to the development of a national strategy for controlling invasive alien plant species: The case of Parthenium hysterophorus in South Africa. Bothalia 46:. doi: 10.4102/abc.v46i1.2053

Tsanuo MK, Hassanali A, Hooper AM, et al (2003) Isoflavanones from the allelopathic aqueous root exudate of Desmodium uncinatum. Phytochemistry 64:265-273. doi: 10.1016/S0031-9422(03)00324-8

Yu X, Zheng S, Zheng M, et al (2018) Herbicide accumulations in the Xingkai lake area and the use of restored wetland for agricultural drainage treatment. Ecological Engineering 120:260-265. doi: 10.1016/j.ecoleng.2018.06.009

Witt, A., Beale, T., van Wilgen, B.W., 2018. An assessment of the distribution and potential ecological impacts of invasive alien plant species in eastern Africa. Transactions of the Royal Society of South Africa. 73, 217-236. https://doi.org/10.1080/0035919X.2018.1529003

Zhao H-B, Wu J-R, Xiao H-L, Chen B-M (2008) Allelopathic potential of native plants on invasive plant Mikania micrantha H.B.K. in South China. Allelopathy Journal 22(1):189-196 22:189-196 